\title{
Role of Rural Women in Agriculture Activities in Jaipur District of Rajasthan, India
}

\author{
Seema Yadav", N.K. Sharam, Vikas Kumar, Palak Mishra and Sohan Lal Choudhary
}

Department of Extension Education, Sri Karan Narendra Agriculture University, Jobner, Jaipur, India

*Corresponding author

\section{A B S T R A C T}

\section{Keywords}

Role, Participation, Agricultural activities, Rural women

Article Info

Accepted:

28 January 2018

Available Online:

10 February 2018

\begin{abstract}
Participation of women is not limited to agricultural activities only but they are contributing significantly towards livestock management. The study is an in depth analysis of participation of women in various agricultural activities. Therefore, the rural women play a significant role in agricultural activities such as seeding, transplanting, weeding, fertilizer application, plant protection, harvesting, processing, storage etc. Several of these operations are carried out by women only. The present study was conducted in Jaipur region of Rajasthan. Out of five districts in Jaipur region, Jaipur district was selected. From selected district, two panchayat samities (Dudu and Jalsu) were selected randomly by using simple random sampling. From the selected panchayat samities five villages from each panchayat samiti were selected by using simple random sampling. Similarly, from 10 selected villages 120 respondents were selected by proportionate random sampling technique.
\end{abstract}

\section{Introduction}

In Indian society, women have a multidimensional role. The largest numbers of women in India are engaged in farming operations either as cultivators or as supervisors or as agricultural labourers. They are the main participants and decision makers in various agricultural operations like seed sowing, transplanting, weeding, harvesting, threshing, application of manure, storage of seeds and food grains and post-harvest home level processing. Apart from all these they are also involved in bringing fodder from field, chaff cutting, feeding and cleaning of cattle, maintaining cattle shed, compost making etc.
Women are actively involved in pre-sowing, harvesting and post-harvesting operations as well as allied activities.

The jobs traditionally done by farm women in the order of importance are mainly the kitchen gardening, seedling raising and transplanting.

Women involvement in agricultural operations is besides their usual domestic work. Most of the contributions made by women to the farm sector also go unaccounted as they are not directly paid. The contribution of female labour towards agricultural production is always more than the male labour in all types of land holding size. 
Materials and Methods

\section{Study area}

The present study was conducted in Jaipur region of Rajasthan. Out of five districts in Jaipur region, Jaipur district was selected. From selected district, two panchayat samities (Dudu and Jalsu) were selected randomly by using simple random sampling. From the selected panchayat samities five villages from each panchayat samiti were selected by using simple random sampling.

\section{Sampling procedure and Sample size}

From 10 selected villages 120 respondents were selected by proportionate random sampling technique.

\section{Data collection}

The investigator collected data by using personal interview method. The collected data were analyzed by using Mean Percent score (MPS). The Mean Percent score obtained by multiplying total obtained score of the respondents divided by the maximum obtainable score under each practice. The following statistical methods were used in the present study.

\section{Mean score}

It is obtained by total score of each statement divided by total number of rural women.

\section{Mean Percent Score (MPS)}

Mean percent scores were obtained by multiplying total obtained score of the respondents by hundred and divided by the maximum obtainable score under each practice.

Formula of MPS is given as under:
Total score obtained by the respondents MPS = Maximum obtainable score

\section{Results and Discussion}

\section{Role of rural women in agricultural activities}

\section{Pre sowing and sowing activities}

It is evident from data presented in table 1 that the most important role played by the rural women under pre sowing and sowing activities was in "Pre sowing irrigation" (MPS 87.22 ) as it was perceived to the highest extent by rural women. The second most important role played by the rural women was in "Manuring of fields" (MPS 79.44) followed by "Maintenance of agriculture implements" (MPS 76.10), "Sowing of seeds and transplanting" (MPS 66.94) "Raising vegetable nursery" (MPS 66.10) and "Seed treatment" (MPS 55.83), which were ranked, Third, Fourth, Fifth and Sixth respectively. While, "Land preparation" (MPS 24.21) and "Application of basal dose of fertilizers" (MPS 24.16) were found to be in 'less extent' category of role played by the rural women. Saini and Koppen (2001) and also supported the current findings (Fig. 1).

\section{Intercultural activities}

It is further evident from data presented in table 1 that the most important role played by the rural women in intercultural activities was under "Intercultural operation (weeding and hoeing)" (MPS 96.66) as it was perceived to the highest extent by rural women. The second most important role played by the rural women was in "Harvesting (a. Cutting, b. Drying)" (MPS 94.44) followed by "Irrigation" (MPS 86.10) and "Gaps filling" (MPS 84.66), which were ranked Third and Fourth respectively. While, "Application of 
fertilizer (Top dressing)" (MPS 28.33) and "Plant protection (a. spraying, b. dusting)" (MPS 26.11) were found to be under the category 'less extent' role played by the rural women in intercultural activities. The findings of Singh (2011) in line with the findings of the study.

\section{Post-harvest activities}

It is evident from data presented in table 1 that the most important role played by the rural women in post-harvest activities was under "Threshing" (MPS 82.22) as it was perceived to the highest extent by rural women. The second most important role played by the rural women was under "Winnowing and cleaning" (MPS 72.49) followed by "Storing and treating grain" (MPS 64.71) and "Transportation of the produce to threshing floor" (MPS 62.77) which were ranked, Third and Fourth respectively. While, "Weighing and bagging" (MPS 46.38) "Loading of food grain and fodder into carts" (MPS 39.16) were found to be under 'less extent' category of role played by the rural women in post-harvest activities. Humera et al., (2009) also supported the current findings.

\section{Role of rural women in agricultural} activities in Dudu panchayat samiti

\section{Pre sowing and sowing activities}

It is evident from data presented in table 1 that the most important role played by the rural women in pre sowing and sowing activities in Dudu panchayat samiti was under "Pre sowing irrigation" (MPS 83.33) as it was perceived to the highest extent by rural women. The second most important role played by the rural women was under "Manuring of fields" (MPS 71.66) followed by "Maintenance of agriculture implements" (MPS 69.44), "Raising vegetable nursery" (MPS 59.44), "Sowing of seeds and transplanting" (MPS 58.33) and "Seed treatment" (MPS 55.55), which were ranked, Third, Fourth, Fifth and Sixth, respectively. While, "Land preparation" (MPS 27.77) and "Application of basal dose of fertilizers" (MPS 21.66) were found to be under the category of 'less extent' role played by the rural women in pre sowing and sowing activities in Dudu panchayat samiti. It could be further inferred that the participation in pre sowing and sowing activities of Jalsu panchayat samiti's rural women (MPS 64.09) was comparatively higher than Dudu panchayat samiti's rural women (MPS 55.55).

\section{Intercultural activities}

It is evident from data presented in table 1 that the most important role played by the rural women in intercultural activities in Dudu panchayat samiti was under "Intercultural operation (Weeding and hoeing)" (MPS 97.22) as it was perceived to the highest extent by rural women. The second most important role played by the rural women was under "Harvesting (a. Cutting, b. Drying)" (MPS 95.55) followed by "Irrigation" (MPS 91.66) and "Gaps filling" (MPS 85.55), which were ranked Third and Fourth respectively. While, "Application of fertilizer (Top dressing)" (MPS 30.55) and "Plant protection (a. Spraying, b. dusting)" (MPS 26.11) were found to be under 'less extent, category of role played by the rural women in intercultural activities in Dudu panchayat samiti. It could be further inferred that the participation in intercultural activities of Dudu panchayat samiti's rural women (MPS 71.11) was comparatively higher than the Jalsu panchayat samiti's rural women (MPS 66.66).

\section{Post-harvest activities}

It is also evident from data presented in table 1 that the most important role played by the rural women in post-harvest activities in Dudu panchayat samiti was under "Threshing" (MPS 85.00) as it was perceived to the highest extent by rural women. 
Fig.1 Role of rural women in agricultural activities

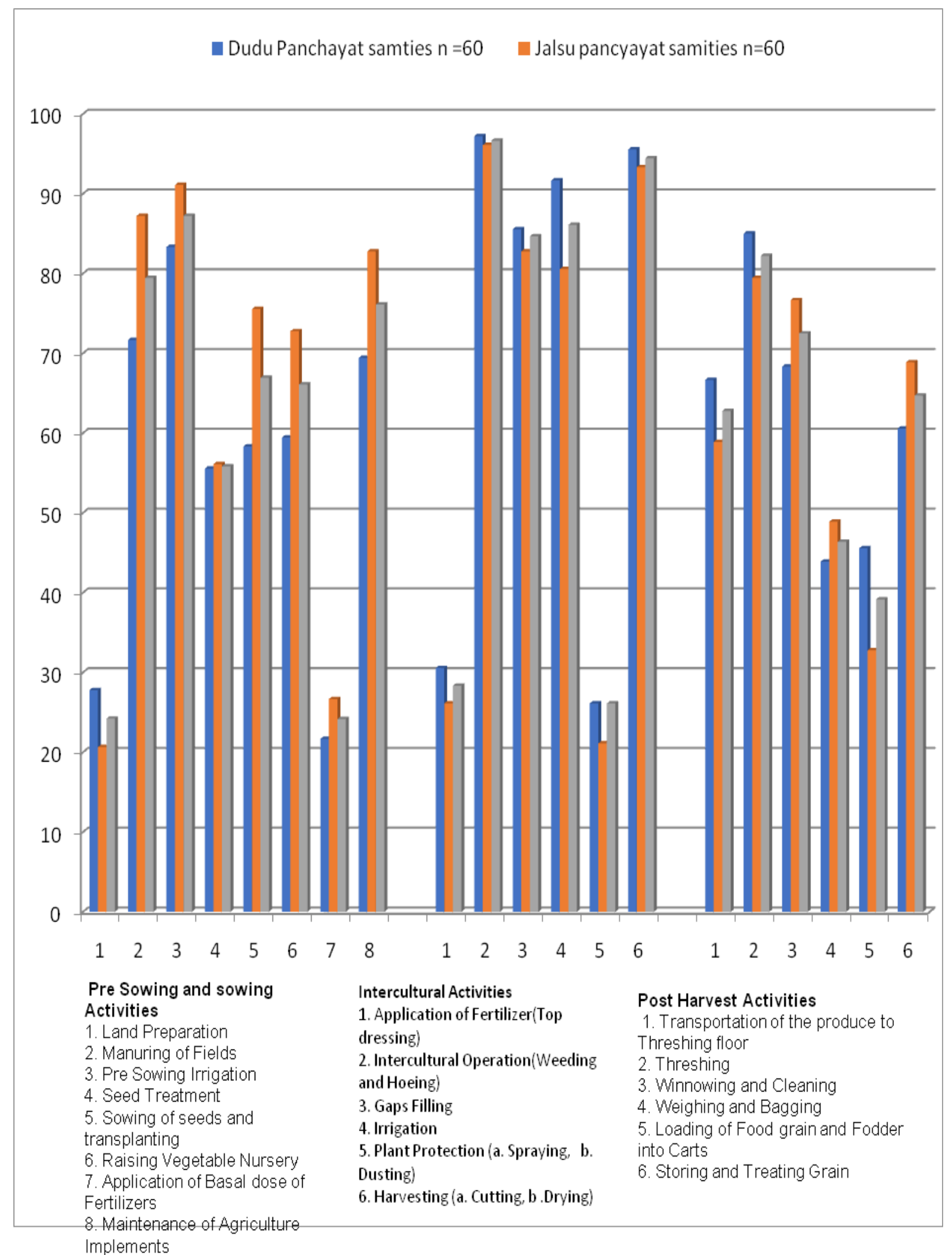


Table.1 Role of rural women in agricultural activities

\begin{tabular}{|c|c|c|c|c|c|c|c|}
\hline \multirow[t]{3}{*}{ S.no. } & \multirow[t]{2}{*}{ Agricultural activities } & \multicolumn{6}{|c|}{ Mean percent scores obtained } \\
\hline & & $\begin{array}{l}\text { Dudu } \\
n=60\end{array}$ & Rank & $\begin{array}{l}\text { Jalsu } \\
\mathrm{n}=60\end{array}$ & Rank & $\begin{array}{c}\text { Overall } \\
n=120\end{array}$ & Rank \\
\hline & Pre sowing and sowing activities & & & & & & \\
\hline 1. & Land preparation & 27.77 & VII & 20.66 & VIII & 24.21 & VII \\
\hline 2 & Manuring of fields & 71.66 & II & 87.22 & II & 79.44 & II \\
\hline 3. & Pre sowing irrigation & 83.33 & I & 91.11 & I & 87.22 & I \\
\hline 4. & Seed treatment & 55.55 & VI & 56.11 & VI & 55.83 & VI \\
\hline 5. & Sowing of seeds and transplanting & 58.33 & $\mathrm{~V}$ & 75.55 & IV & 66.94 & IV \\
\hline 6. & Raising vegetable nursery & 59.44 & IV & 72.77 & $\mathrm{~V}$ & 66.10 & V \\
\hline 7. & Application of basal dose of fertilizers & 21.66 & VIII & 26.66 & VII & 24.16 & VIII \\
\hline \multirow[t]{2}{*}{8.} & Maintenance of agriculture implements & 69.44 & III & 82.77 & III & 76.10 & III \\
\hline & Intercultural activities & & & & & & \\
\hline 1. & Application of fertilizer (Top dressing) & 30.55 & $\mathrm{~V}$ & 26.11 & V & 28.33 & V \\
\hline 2. & Intercultural operation (Weeding and hoeing) & 97.22 & I & 96.11 & I & 96.66 & I \\
\hline 3. & Gaps filling & 85.55 & IV & 82.77 & III & 84.66 & IV \\
\hline 4. & Irrigation & 91.66 & III & 80.55 & IV & 86.10 & III \\
\hline 5. & Plant protection (a. Spraying, b. Dusting) & 26.11 & VI & 21.11 & VI & 26.11 & VI \\
\hline \multirow[t]{2}{*}{6.} & Harvesting (a. Cutting, b. Drying) & 95.55 & II & 93.33 & II & 94.44 & II \\
\hline & Post-harvest activities & & & & & & \\
\hline 1. & Transportation of the produce to threshing floor & 66.66 & III & 58.88 & IV & 62.77 & IV \\
\hline 2. & Threshing & 85.00 & I & 79.44 & I & 82.22 & I \\
\hline 3. & Winnowing and cleaning & 68.33 & II & 76.66 & II & 72.49 & II \\
\hline 4. & Weighing and bagging & 43.88 & VI & 48.88 & V & 46.38 & V \\
\hline 5. & Loading of food grain and fodder into carts & 45.55 & V & 32.77 & VI & 39.16 & VI \\
\hline 6. & Storing and treating grain & 60.55 & IV & 68.88 & III & 64.71 & III \\
\hline
\end{tabular}

The second most important role played by the rural women was under "Winnowing and cleaning" (MPS 68.33) followed by "Transportation of the produce to threshing floor" (MPS 66.66) and "Storing and treating grain" (MPS 60.55), which were ranked, Third and Fourth, respectively. While, "Loading of food grain and fodder into carts" (MPS 45.55) and "Weighing and bagging" (MPS 43.88) were found to be under 'less extent' category of role played by the rural women in post-harvest activities in Dudu panchayat samiti.

It could be further inferred that the participation in post-harvest activities of Dudu panchayat samiti's rural women (MPS 61.66) was comparatively higher than the Jalsu panchayat samiti's rural women (MPS 60.92).
Role of rural women in agricultural activities in Jalsu panchayat samiti.

\section{Pre sowing and sowing activities}

It is evident from data presented in table 1 that the most important role played by the rural women in pre sowing and sowing activities in Jalsu panchayat samiti was under "Pre sowing irrigation" (MPS 91.11) as it was perceived to the highest extent by rural women. The second most important role played by the rural women was under "Manuring of fields" (MPS 87.22) followed by "Maintenance of agriculture implements" (MPS 82.77), "Sowing of seeds and transplanting" (MPS 75.55) and "Raising vegetable nursery" (MPS 72.77), "Seed treatment" (MPS 56.11) which were ranked, Third, Fourth, Fifth and Sixth respectively. 
While, "Application of basal dose of fertilizers" (MPS 26.66) and "Land preparation" (MPS 20.55) and were found to be under 'less extent' category of role played by the rural women in pre sowing and sowing activities in Jalsu panchayat samiti.

\section{Intercultural activities}

It is evident from data presented in table 1 that the most important role played by the rural women in intercultural activities in Jalsu panchayat samiti was under "Intercultural operation (Weeding and hoeing)" (MPS 96.11) as it was perceived to the highest extent by rural women. The second most important role played by the rural women was under "Harvesting (a. Cutting, b. Drying)" (MPS 93.33) followed by "Gaps filling" (MPS 82.77), "Irrigation" (MPS 80.55) which were ranked Third and Fourth respectively. While, "Application of fertilizer (Top dressing)" (MPS 26.11) and "Plant protection (a. Spraying, b. dusting)" (MPS 21.11) were found to be under 'less extent' category of role played by the rural women in intercultural activities in Jalsu panchayat samiti.

\section{Post-harvest activities}

It is evident from data presented in table 1 that the most important role played by the rural women in post-harvest activities in Jalsu panchayat samiti was under "Threshing" (MPS 79.44) as it was perceived to the highest extent by rural women. The second most important role played by the rural women was under "Winnowing and cleaning" (MPS 76.66) followed by "Storing and treating grain" (MPS 68.88) and "Transportation of the produce to Threshing floor" (MPS 58.88) which were ranked Third and Fourth respectively. While, "Weighing and bagging" (MPS 48.88) and Loading of food grain and fodder into carts" (MPS 32.77) were found to be under 'less extent' category of role played by the rural women in postharvest activities in Jalsu panchayat samiti.

It was found that the majority 62.5 per cent of the total rural women were from medium level of participation in agricultural activities. It was followed by 21.67 per cent rural women with high level of participation in agricultural activities, while 15.83 per cent rural women were reported under the category of low level of participation in agricultural activities.

It was found that the majority of rural women had highest participation in "pre sowing irrigation" (MPS 87.22), whereas a less number of rural women who participated rarely in "Application of basal dose of fertilizers" (MPS 24.16) in pre sowing and sowing agricultural activities.

It was found that the majority of rural women had highest participation in "Intercultural operation (weeding and hoeing)" (MPS 96.66), whereas a less number of rural women who participated rarely in "Plant protection (a. Spraying, b. Dusting)" (MPS 26.11) in intercultural activities.

It was found that the majority of rural women had highest participation in "Threshing" (MPS 82.22), whereas a less number of rural women who participated rarely in "Loading of food grain and fodder into carts post" (MPS 39.16) in post-harvest agricultural activities.

\section{References}

Humera, Amin, Tanvir, Ali, Munir, Ahmad and Zafar, M. I. (2009). Participation level of rural women in agricultural activities. Pakistan Journal. Agril. Sci. 46 (4). 
Saini, H., \& van Koppen, B. (2001). Gender in Lift Irrigation Schemes in East Gujarat, India. Working Paper 11. International Water Management Institute, Colombo, Sri Lanka.
Singh, Sarita, (2011). A critical study on participation of rural women in agriculture activities Hoshangabad district M.P. M.Sc. (Ag.) Thesis (unpublished), JNKVV, Jabalpur.

\section{How to cite this article:}

Seema Yadav, N.K. Sharam, Vikas Kumar, Palak Mishra and Sohan Lal Choudhary. 2018. Role of Rural Women in Agriculture Activities in Jaipur District of Rajasthan, India. Int.J.Curr.Microbiol.App.Sci. 7(02): 3549-3555. doi: https://doi.org/10.20546/ijcmas.2018.702.421 